\title{
Application of Catalysts to Metal Microreactor Systems
}

\author{
Pfeifer Peter \\ Institute for Micro Process Engineering, Karlsruhe Institute of Technology,
}

Germany

\section{Introduction}

Applying microsystems for heterogeneously catalyzed processes means that the surface of tiny channels or structures has to be functionalized. Considering the surface-to-volume ratio of microchannels, volume specific surfaces of microchannels in the order of $10^{5}$ up to $10^{6} \mathrm{~m}^{2} / \mathrm{m}^{3}$ can be obtained. However, when combining the channels to reactors the entire fabrication technique and the necessary connection to conventional equipment lowers the overall surface-to-volume ratio to roughly $2^{*} 10^{3}$ up to $2^{*} 10^{4} \mathrm{~m}^{2} / \mathrm{m}^{3}$ and thus increases costs for materials and manufacture. Taking into account the demand of catalysis, i.e. the necessary "edges and corners" of the active species and the surface area of conventional catalyst support materials of $10^{7}$ up to $10^{9} \mathrm{~m}^{2} / \mathrm{m}^{3}$, the surface-to-volume ratio of the microsystems is not necessarily sufficient. Reviewing the literature only few cases are reported, where the geometric surface of the microsystem, e.g. channels made in copper or silver metal, is high enough ensuring cost competitive micro process engineering equipment. The reaction rates per surface site need to be very high, so that the volume specific heat flux is in a range that the advantage of microsystems, i.e. the high heat transfer rates, can be utilized for improving chemical processes in terms of process intensification.

Two approaches are often applied for increasing the geometric surface, the application of a micro fixed bed, also often called "packed bed microreactors", or the surface coating with support material and catalytically active species. Regarding the process requirements it is obvious that both approaches have Pros and Cons. So for example, commercial catalyst can directly be applied for the packed bed system while catalyst coating may take a serious time for its development. Catalysts can be removed in packed bed arrangements whereas the coating may only be removed with the whole microreactor. On the other hand coating technology provides new insights into catalysis due to quasi isothermal conditions so that much higher activity of the catalysts can be applied or obtained.

This book chapter will give information on interplay between reaction engineering aspects, material science and microfabrication which have to be considered when developing a specific heterogeneously catalysed microreactor process. A brief introduction in the individual coating approaches and exemplarily in new coating developments will be given. 


\section{Reaction engineering, materials and fabrication interplay}

A whole set of parameters listed in Table 1 has to be considered for every kind of application and there is no easy decision for a specific catalyst integration technique. For decision making, the issues which have to be considered can be divided into three sets of categories, a) the reaction engineering, i.e. the catalyst and reaction dependent, b) the materials linked with preparation methods and c) the implications from microstructure fabrication and process.

\begin{tabular}{|c|c|c|}
\hline $\begin{array}{c}\text { Catalyst and reaction } \\
\text { dependent issues }\end{array}$ & $\begin{array}{c}\text { Method and material } \\
\text { dependent issues }\end{array}$ & $\begin{array}{l}\text { Implications of micro- } \\
\text { fabrication and process }\end{array}$ \\
\hline Volume specific catalyst & Homogeneous & Deactivation rate versus \\
\hline loading & distribution of catalyst & regeneration / removal \\
\hline $\begin{array}{l}\text { Mass specific activity of } \\
\text { catalyst }\end{array}$ & Thermal expansion & Reactor joining method \\
\hline $\begin{array}{l}\text { Heat of reaction and heat } \\
\text { transport/transfer }\end{array}$ & $\begin{array}{l}\text { Adhesion (stationary / } \\
\text { transient operation) }\end{array}$ & $\begin{array}{l}\text { Stacking schemes and } \\
\text { modular approaches }\end{array}$ \\
\hline $\begin{array}{l}\text { Catalyst and reactor } \\
\text { costs }\end{array}$ & Chemical compatibility & Migration effects \\
\hline Mass transport/transfer & Development effort & $\begin{array}{c}\text { Reactor size implications } \\
\mathrm{T} / \mathrm{p} \text {-requirements }\end{array}$ \\
\hline
\end{tabular}

Table 1. Categories for decision on packed bed microreactor versus various options of catalyst wall coatings in microreactors for heterogeneous catalysis

\subsection{Reaction engineering aspects}

From reaction engineering point of view it is not only the single parameter, i.e. the ratio of catalyst amount to mass of the reactor or the mass specific activity of the catalyst which determines the choice. It is often a combination such as the product flow per reactor mass which is a major parameter since it combines the activity of the catalyst with the occupied volume ratio of the catalyst inside the microreactor. In the following subsections the headings refer basically to the items in Table 1 - except for the latter issue - and details the individual aspects.

\subsubsection{Product flow per reactor mass}

Klemm et al. (2007) pointed out by a simple geometric analysis that, in comparison to a normal packed bed multi-tubular reactor, microchannel reactors suffer from small volume specific catalyst loading unless the coating layer occupies almost half the volume of the microchannels. For their comparison they assumed the same catalyst working in microchannel and the standard fixed bed under microkinetic regime, i.e. that the pore effectiveness $(\eta)$ is unity. Their analysis was slightly more favourable for the microreactor in a comparison to a core-shell catalyst or at an effectiveness factor of 0.3 in conventional equipment. However, they did not explicitly mention that other possibilities of catalyst integration such as the packed bed microreactor or the use of non-standard catalysts with higher mass specific activity is feasible under excellent temperature control. 
In Pfeifer et al. (2011) this comparison was extended for the packed bed microreactor approach, showing that, with different catalyst systems for the oxidation reaction of $\mathrm{SO}_{2}$ to $\mathrm{SO}_{3}$, both approaches can be competitive with conventional tubular reactors (Table 2).

\begin{tabular}{l|ccccc}
\hline \multicolumn{1}{c|}{ System } & $\begin{array}{c}\mathbf{V}_{\text {cat }} / \mathbf{V}_{\text {react }} \\
\text { or } \%\end{array}$ & $\begin{array}{c}\mathbf{m}_{\text {Stainless }} / \mathbf{V}_{\text {cat }} \\
\mathbf{t} / \mathbf{m}^{3}\end{array}$ & $\begin{array}{c}\mathbf{m}_{\text {Stainless }} \\
\mathbf{m}_{\text {cat }}\end{array}$ & $\begin{array}{c}\text { Cat.-Activity } \\
\mathbf{k g} / \mathbf{k g h}\end{array}$ & $\begin{array}{c}\mathbf{m}_{\text {Stainless }} /\left(\mathbf{m}_{\text {Product }}{ }^{*} \mathbf{t}\right) \\
\mathbf{k g h} / \mathbf{k g}\end{array}$ \\
\hline $\begin{array}{l}\text { Packed bed } \\
\text { (bundle) } \eta=1\end{array}$ & $12-15^{*}$ & $10^{*}$ & $4.2^{*}$ & 2 & 2.1 \\
$\begin{array}{l}\text { Packed bed } \\
\text { (bundle) } \eta=0.3\end{array}$ & $4-5^{*}$ & $30^{*}$ & $12.6^{*}$ & 2 & 6.3 \\
$\begin{array}{l}\text { Micro packed bed } \\
\text { (commercial }\end{array}$ & 52.7 & 5.4 & 2.3 & 1.8 & 1.3 \\
$\begin{array}{l}\mathrm{V}_{2} \mathrm{O}_{5} / \mathrm{SiO}_{2} \text { catalyst) } \\
\text { Coated channel } \\
\text { (Pt/TiO } \text { catalyst) }\end{array}$ & 1.3 & 251.5 & 105.3 & 30.1 & 3.5 \\
\hline
\end{tabular}

Table 2. Comparison of catalyst volume fraction and influence of catalyst productivity in the oxidation of $\mathrm{SO}_{2}$ to $\mathrm{SO}_{3}$ on product flow per reactor mass (* data from Klemm et al. (2007)).

\subsubsection{Heat of reaction and heat transport/transfer}

The catalyst loading and the catalyst implementation route are strongly linked with the heat of reaction. Since the intention for the use of a microreactor is a good temperature control in the reaction fluid and the catalyst, a severe temperature gradient should be avoided. Regarding the criteria for evaluation of temperature gradients in a packed bed microreactor design it is possible to reduce the complexity of calculation to a 2-D geometrical similar tubular design or a 2-D slit design. Then it is possible to calculate temperature gradients in the micro packed bed with simplified heat balance. Knochen et al. (2010) have analysed the microreactor performance under the aspect of microchannel slit height for the FischerTropsch synthesis reaction and came to the conclusion that even at $1.5 \mathrm{~mm}$ slit height the system works nearly isothermal.

For a possible heat transfer limitation particle-to-fluid the equation from Mears (1971) can be applied to the packed bed microreactor (Eq. 1). The same is true for a possible heat transport limitation within the catalyst particle (Anderson (1963), Eq. 2).

$$
\begin{array}{cc}
\frac{\left(-\Delta \mathrm{H}_{\mathrm{R}}\right) \mathrm{r}_{\mathrm{v}, \text { eff }} \mathrm{r}_{\mathrm{p}}{ }^{2}}{(1-\varepsilon) \lambda_{\mathrm{cat}}^{\text {eff }} \mathrm{T}_{\mathrm{s}}} \frac{\mathrm{E}_{\mathrm{A}}}{\mathrm{RT}}<1 & 0.95 \leq \eta \leq 1.05 \\
\frac{\left(-\Delta \mathrm{H}_{\mathrm{R}}\right) \mathrm{r}_{\mathrm{v}, \text { eff }} \mathrm{r}_{\mathrm{p}}}{(1-\varepsilon) \mathrm{a}_{\mathrm{p}, \mathrm{g}} \mathrm{T}_{\mathrm{g}}} \frac{\mathrm{E}_{\mathrm{A}}}{\mathrm{RT}}<0.15 & 0.95 \leq \eta \leq 1.05
\end{array}
$$

For the negligible heat transport limitations in the case of the wall-coated microreactor the equations have to be different due to the geometric changes for derivation of the criteria. Looking at Fig. 1 it becomes clear that two cases have to be distinguished with regard to the microreactor stacking scheme: A) the strictly cooled case and B) the monolithic system, where most of the channels with reaction are located next to each other. 


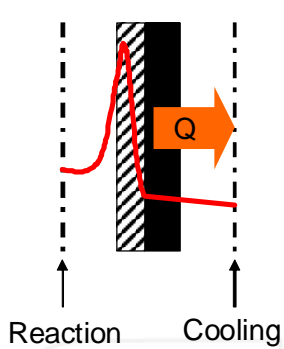

(stacking 1:1)

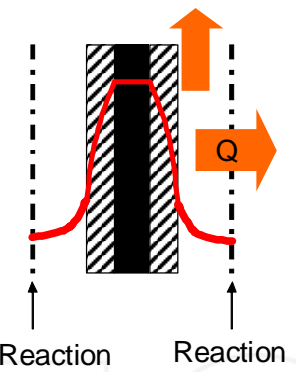

(Monolith, e.g. ATR)

Fig. 1. Two cases which have to be distinguished for heat transfer limitation: a strictly cooled system (left) and a monolithic system (right). The different directions of heat flux and the temperature profiles are indicated (porous catalyst $=$ shaded, microreactor wall $=$ black).

Due to the fact that the microsystem usually operates in the region of laminar flow (small Reynolds numbers) the following order of heat resistances can be applied:

$$
\mathrm{a}_{\mathrm{g}}=\frac{\lambda_{\mathrm{g}}}{\delta_{\mathrm{g}}} \approx \frac{\lambda_{\mathrm{g}}}{\mathrm{r}_{\text {channel }}}<<\frac{\lambda_{\text {cat }}^{\text {eff }}}{\delta_{\text {cat }}}<<\frac{\lambda_{\text {wall }}}{\mathrm{s}_{\text {wall }}}
$$

That means that the maximum temperature in case A is near to the gas phase and almost all heat flux is transferred to the cooling fluid, when the cooling is effective. By approximation of the temperature profile in the catalyst as almost linearly falling instead of the real unsymmetric parabolic profile, one can derive a modified Anderson criteria like Eq. 4, which was published in Görke et al. (2009). The heat transport to the gas mixture is not relevant in case A.

$$
\frac{\left(-\Delta \mathrm{H}_{\mathrm{R}}\right) \mathrm{r}_{\mathrm{v}, \text { eff }}\left(\frac{\mathrm{V}_{\text {cat }}}{\mathrm{O}_{\text {cat, geo }}}\right)^{2}}{\lambda_{\text {cat }}^{\text {eff }} \mathrm{T}_{\mathrm{R}}} \frac{\mathrm{E}_{\mathrm{A}}}{\mathrm{RT}_{\mathrm{R}}}<0.1
$$

For case B the monolithic system, the heat transport to the reaction fluid has to be considered instead. Eq. 5 has been published in Görke et al. (2009).

$$
\frac{\left(-\Delta \mathrm{H}_{\mathrm{R}}\right) \mathrm{r}_{\mathrm{v}, \text { eff }} \frac{\mathrm{V}_{\text {cat }}}{\mathrm{O}_{\text {cat,geo }}}}{\mathrm{a}_{\mathrm{g}} \mathrm{T}_{\mathrm{R}}} \frac{\mathrm{E}_{\mathrm{A}}}{\mathrm{RT}_{\mathrm{R}}}<0.05
$$

The missing porosity factor in Eqs. 4,5 compared to 1,2 is due to different assumptions for the reaction rate, i.e. the change in volume due to wall coating is assumed to be negligible.

The heat conduction along the walls of the microreactor is difficult to describe by one criterion. So a pseudo-homogenous approach for the description is necessary (see section 2.3.5).

Taking into account the maximum possible slit height of the reactor or the maximum coating thickness from reaction aspects, influence on the material aspects is obvious. 


\subsubsection{Catalyst and reactor costs}

Catalyst costs and reactor costs may significantly change with respect to the issues which have been raised above. Higher catalyst loadings and higher allowed temperature gradients will decrease the cost of investment but temperature gradients might also increase the costs for catalyst removal due to faster deactivation. With regard to the choice of the catalyst implementation technique the costs for the catalyst might differ due to different species, i.e. when noble metals are needed for high activity in the coated system and lower specific costs can be obtained with the micro packed bed, the deactivation rate might influence the decision for the catalyst implementation method. In both cases a cost competitive system should be obtained in comparison to tubular reactors or other techniques like the fluidized bed apparatus.

Approaches for mass production of catalyst layers, i.e. reducing the coating cost are rarely reported. A cheap possibility has been demonstrated by O'Connell et al. (2011) by screen printing in the application of micro-engineered fuel reformers for hydrogen production. Such a coating is shown in Fig. 2.

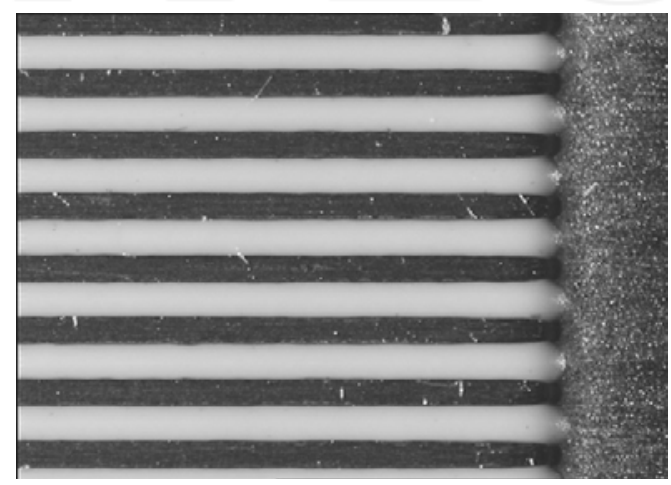

Fig. 2. Picture of an individual microchannel plate after screen printing, taken from O'Connell et al. (2011).

\subsubsection{Mass transport or transfer}

Due to short diffusion pathways in the microsystem, the overall mass transport in the phases or the transfer via phase boundaries is often magnitudes higher than in conventional reactor systems. However, with regard to the desired high loadings with catalyst and low cost for fluid compression or pumping, the mass transfer to the catalyst and the mass transport within porous catalyst still has to be effective. As for the heat transport the differentiation between packed bed and wall-coated microreactor is necessary for mass transport considerations. The mass transport in packed bed microreactors is not significantly different to normal tubular packed bed reactors, so that equations like the Mears criteria (Eq. 6) can be used.

$$
\frac{\mathrm{r}_{\mathrm{v}, \text { eff }} \mathrm{r}_{\mathrm{p}}}{(1-\varepsilon) \mathrm{k}_{\mathrm{g}} \mathrm{c}_{\mathrm{i}, \mathrm{bulk}}}<\frac{0.15}{\mathrm{n}}
$$

The assumption of laminar flow can be used to substitute the gas transport coefficient by the ratio of the diffusion coefficient of the reaction species in the mixture and half of the mean 
distance between the particles. Diffusion limitation in the pores of the catalyst particles can be excluded by the Weisz-Prater criteria (Eq. 7).

$$
\frac{r_{v, \text { eff }} r_{p}^{2}}{(1-\varepsilon) D_{i}^{\text {eff }} c_{i, g}}<1 \quad \eta>0.95 \quad n \neq 0
$$

In the case of the wall-coated microchannel system Eq. 6 rewrites in the form of Eq. 8 (Görke et al. (2009)) due to the accessible geometric surface of the catalyst is different and the mass balance between transport to the surface and the reaction in the catalyst has to be fulfilled.

$$
\frac{\mathrm{r}_{\mathrm{v}, \text { eff }} \frac{\mathrm{V}_{\text {cat }}}{\mathrm{O}_{\text {cat,geo }}}}{\mathrm{k}_{\mathrm{g}} \mathrm{c}_{\mathrm{i}, \text { bulk }}}<\frac{0.05}{\mathrm{n}}
$$

Again, the mass transport coefficient can be substituted by the ratio of the diffusion coefficient in the gas phase with the diffusion pathway, which is the radius of the free cross section or the radius of the microchannel minus the catalyst coating thickness (Eq. 9).

$$
\frac{\mathrm{r}_{\mathrm{v}, \text { eff }}\left(\mathrm{r}_{\text {channel }}-\delta_{\text {cat }}\right) \frac{\mathrm{V}_{\text {cat }}}{\mathrm{O}_{\text {cat,geo }}}}{\mathrm{D}_{\mathrm{i}} \mathrm{c}_{\mathrm{i}, \text { bulk }}}<\frac{0.05}{\mathrm{n}}
$$

This approach has been proven to be valid in simulation work by Lopes et al.(2011). For catalyst coating internal mass transport limitation the Eq. 7 can be transformed to Eq. 10.

$$
\frac{\mathrm{r}_{\mathrm{v}, \text { eff }}\left(\frac{\mathrm{V}_{\text {cat }}}{\mathrm{O}_{\text {cat,geo }}}\right)^{2}}{\mathrm{D}_{\mathrm{i}}^{\text {eff }} \mathrm{c}_{\mathrm{i}, \mathrm{g}}}<0,1 \quad \mathrm{\eta}>0.95 \quad \mathrm{n} \neq 0
$$

The validation of negligible heat transport limitation is only possible via control of observable temperature gradients, e.g. in the cooling fluid or across the reactor walls. A sensor influence is predictable on the temperature measurement due to the small inner structures of the microreactor. In terms of mass transport resistances, some experimental approaches can be used to validate their absence.

Taking into account laminar flow occurring in microstructures, conventional tests like changing the reaction gas velocity at constant weight-hourly space velocity (WHSV) will not result in significant change of the mass transfer to the catalyst as Walter (2003) pointed out. This is due to the fact that in conventional equipment turbulent flow in the conventional packed bed is usually assumed and that the increase in velocity changes the thickness of the laminar boundary layer around the catalyst particle. In both cases, the packed bed microreactor and the wall coated system, this is not valid due to laminar flow. An experimental procedure for wall coated systems was applied by Kölbl et al. (2004). A reduction of total pressure or change of inert gas in the reaction fluid, both at constant reactant pressure, was tested on basis of the calculated change of the diffusion coefficient of the reactant in the reactant mixture. Such procedure has effect on the mass transport to the catalyst and the inner pore diffusion if Knudsen diffusion contributes to mass transport. The same kind of approach was then transferred by Bakhtiary (2010) to the micro packed bed system in which laminar flow is also dominating. Working at high pressure of 5-8 MPa under conditions of methanol synthesis reaction, he tested for a change of the conversion by changing the total pressure and 
the carrier gas while leaving the reactant pressure constant. In both experimental studies it was shown that no mass transport limitation in the gas phase occurred.

Experimental investigations on the mass transport limitations in catalyst layers are much more difficult as discussed by Walter (2003). Only when the change of catalyst layer thickness does not significantly change the free cross section of some microchannel arrangement, an interpretation is possible without changing the channel size either. However, when Knudsen diffusion significantly contributes to the mass transport in the catalyst, a change in the reactant diffusion coefficient could also identify a mass transport resistance in the catalyst. In packed bed microreactors the conventional method of changing the catalyst particle size is applicable for test of catalyst internal mass transport limitation (Bakhtiary (2010)).

A practical approach to overcome a possible problem of diffusion limitation in the catalyst and increasing the catalyst layer thickness is a hierarchical layer structure, which can be obtained in different ways. One way is the use of material which is microporous, i.e. possesses mainly pore diameters in the range of less than $2 \mathrm{~nm}$, and which is brought onto the wall of the microsystem in shape of particles with binders. Materials such as TS1 can be sprayed as particles with diameter of roughly $5 \mu \mathrm{m}$ onto the microchannel substrate and by using adjusted suspensions large pores can be provided (Schirrmeister et al. (2006)). The same result can be obtained by combining so-gel methods and nanoparticles. Görke \& Pfeifer (2011) prepared a catalyst layer from cerium-based sol and $\alpha$-alumina particles with mean particle size of $60 \mathrm{~nm}$ which was impregnated with platinum. This yielded a composition of $13 \mathrm{wt} . \%$ $\mathrm{CeO}_{2}$ on alumina with a surface enlargement $\mathrm{E}$ of $3052 \mathrm{~m}^{2} / \mathrm{m}^{3}$. E is defined according to

$$
\mathrm{E}=\frac{\mathrm{O}_{\text {cat,BET }}}{\mathrm{O}_{\text {wall,geo }}}
$$

Advantage of this procedure is the high catalyst amount of $17 \mathrm{mg} / \mathrm{cm}^{2}$ of microchannel surface. A pure ceria layer based on sol-gel technology would only yield $0.3 \mathrm{mg} / \mathrm{cm}^{2}$ and a surface enlargement of $200 \mathrm{~m}^{2} / \mathrm{m}^{3}$. The nanoparticles provide a thickness increase by factor of higher than 10 but large pores in the range of the particle size. The particle surrounding layer of cerium oxide produces then a large surface area for the introduction of the catalytically active species. A micrograph of the layer in one microchannel is shown in Figure 3.
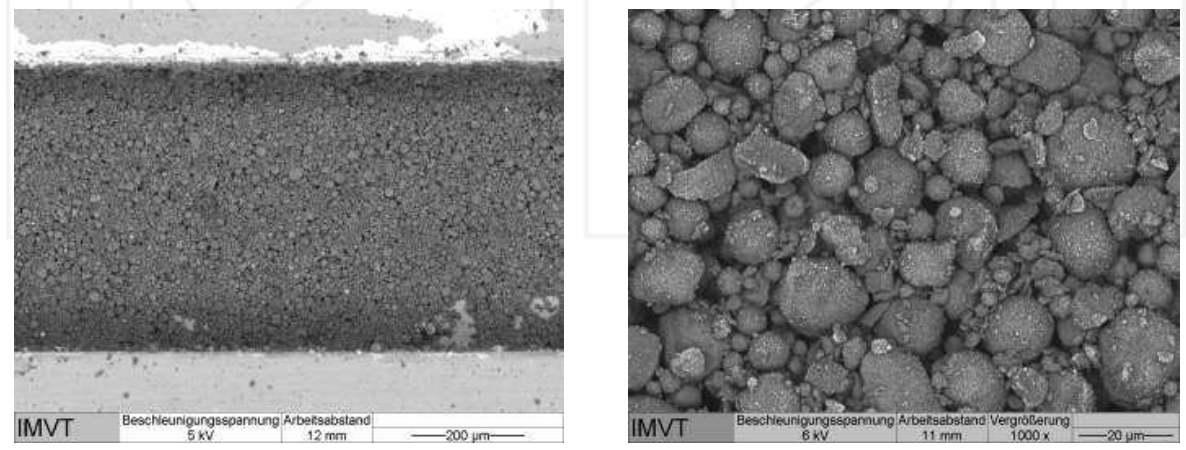

Fig. 3. SEM of a coating with $5 \mathrm{wt}$. $\% \mathrm{Pt}$ on $13 \mathrm{wt}$. $\% \mathrm{CeO}_{2}$ on alumina nanoparticles; left: in one microchannel; right: increased magnification. 


\subsection{Materials and methods}

From a material point of view the chemistry of the interfaces between the microstructure and the catalyst is an important issue. Influence on the catalyst distribution and the adhesion are to be considered and the effort for developing a catalyst coating is essential for its application.

\subsubsection{Homogeneous distribution of catalyst}

Metallic surfaces and small dimensions turn out to be critical issues, when trying to apply catalyst coatings to the microchannel walls. One critical issue is a well-defined residence time. Every microchannel may be taken as a small single reactor. Obviously, different diameters resulting, e.g. from non-uniformity of catalyst layer thickness would lead to different residence times. A simple approach can be used to show the importance for flow distributions. From calculations the pressure drop difference and therefore the mass flow difference between an 80 and a $90 \mu \mathrm{m}$ rectangular channel is approximately $27 \%$ (assuming constant gas velocity). For heterogeneously catalysed reactions the consequences of different hydrodynamic diameters are quite difficult to elucidate, as performance loss is dependent on kinetics of the reactions occurring on the catalyst. However, if the inner diameters of 80 and $90 \mu \mathrm{m}$ are result from a 10 or $5 \mu \mathrm{m}$ thick coating on the channel walls in $100 \mu \mathrm{m}$ channels, respectively, half the catalyst mass and the $27 \%$ flow increase occur in the greater channel. Thus the overall catalyst load, i.e. the flow per catalyst mass increases by $154 \%$ compared to the $10 \mu \mathrm{m}$ thick coating, and totally different conversion or selectivity for the reaction application could be expected in the individual channels.

Important parameters for the homogeneous distribution are the methods and parameters during the preparation of the catalyst layer. An automated spraying technology, reported for example by Schirrmeister et al. (2006), can result in very homogeneous layers. Also drying rate is an important parameter for washcoating, as demonstrated in Pfeifer et al. (2004). However, the most important parameter is the order of manufacturing steps. Catalyst layers can be applied onto open microstructures (pre-coating) or into completely fabricated microdevices (post-coating) as schematically explained in Fig. 4.

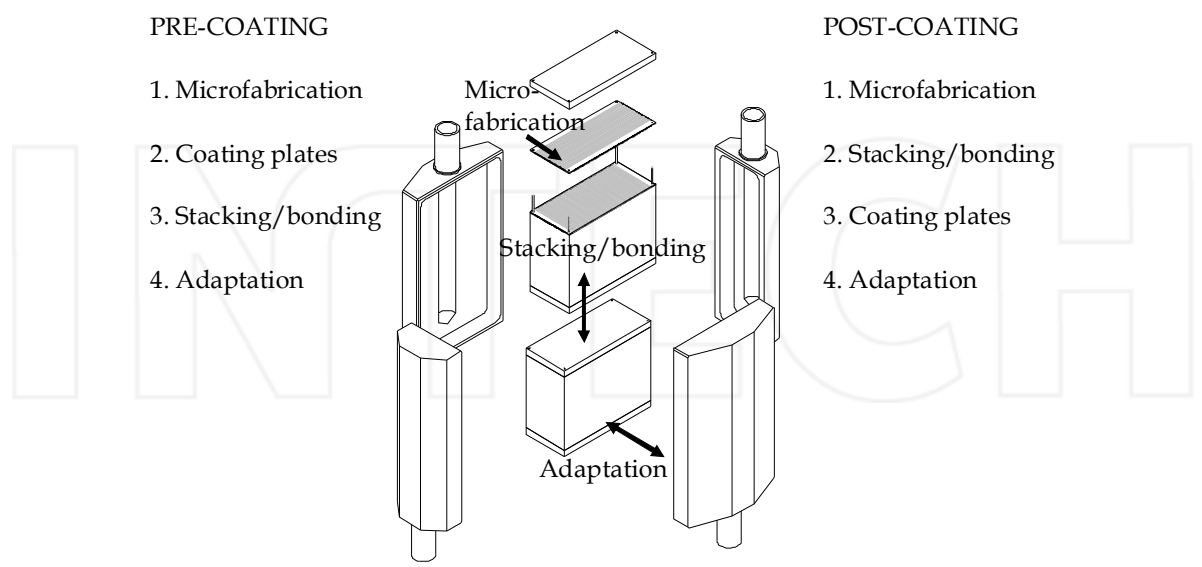

Fig. 4. Fabrication steps of microreactors including two possible routes in the consecutive order of fabrication steps (pre- and post-coating) having influence on the introduction of catalyst; the corresponding microreactor hardware is described in Pfeifer et al. (2009). 
When pre-coating is applied, the subsequent bonding steps must not harm the catalyst system, i.e. no sintering or poisoning may occur. And the bonding step should not be influenced by the sintering process (see section 2.3.2). Otherwise post-coating should be applied. In that case it becomes clear that several of the coating methods can not be used, such as sputtering, spraying, ink-jet or screen printing as they require a direct accessible surface.

SEM pictures of the coatings or cutting the microstructured foils and analysing the distribution of the layer thickness can only give a qualitative impression about coating uniformity. In addition, these methods can only be applied before the microstructured foils are assembled to a complete reactor. Flow distribution has been made more uniform by introduction of regions with high pressure drop, like shown in the review of Rebrov et al. (2011). A practical approach for investigating the uniformity of catalyst layers was developed by help of hot wire anemometry of the gas velocity at the exit of the microchannel array by Pfeifer et al. (2004) and was further developed for 3-D arrangements (Pfeifer \& Schubert (2008)). Work on the flow distribution in micro packed bed systems is currently under progress.

\subsubsection{Thermal expansion}

Due to the fact that most of the applied microreactors are made from metal and that the catalyst support layers are of ceramic nature, the thermal expansion creates large mechanical stress. During preparation of the layers often temperatures of several hundred degrees Celsius are necessary to remove binders or the precursor anion either for the support or the catalytically active species. For reactions on the catalyst, seldom lower temperatures than $100^{\circ} \mathrm{C}$ are sufficient and a start-up of the microreactor to operation temperature is necessary. The factors influencing the thermal shock resistance are the layer thickness, the microchannel shape, and the porosity of the support. Large continuously coated area, increasing thickness, and low porosity reduce the resistance. A high roughness of the microchannel surface can increase the stability and the thermal expansion coefficients can be adjusted in a certain extent to the ceramic material. Materials such as Crofer $22 \mathrm{APU} \circledast$ or alloy 800 , which are adjusted to the properties of the membrane cermets in solid oxide fuel cells, can also be a good choice for catalyst coatings.

\subsubsection{Adhesion}

Adhesion and thermal expansion are very strongly linked, as the sticking properties at low temperature have certainly an effect on the ability of the catalyst layer to stick at higher temperature. Cracks in the surface, however, can still occur while heating the microsystem to the application temperature. The factors improving the adhesion are basically the same as for the thermal resistance. Often intermediate layers are used to adjust the chemical compatibility between the metal surface and the ceramic catalyst support.

The influence of the microfabrication method on the adhesion is clearly visible from the comparison of etched stainless steel versus mechanically fabricated rectangular microchannels in Figure 5. A sol-gel coating of the different microstructures was performed by Kreuder et al. (2011) yielding alumina layers with a thickness of roughly $2 \mu \mathrm{m}$. 

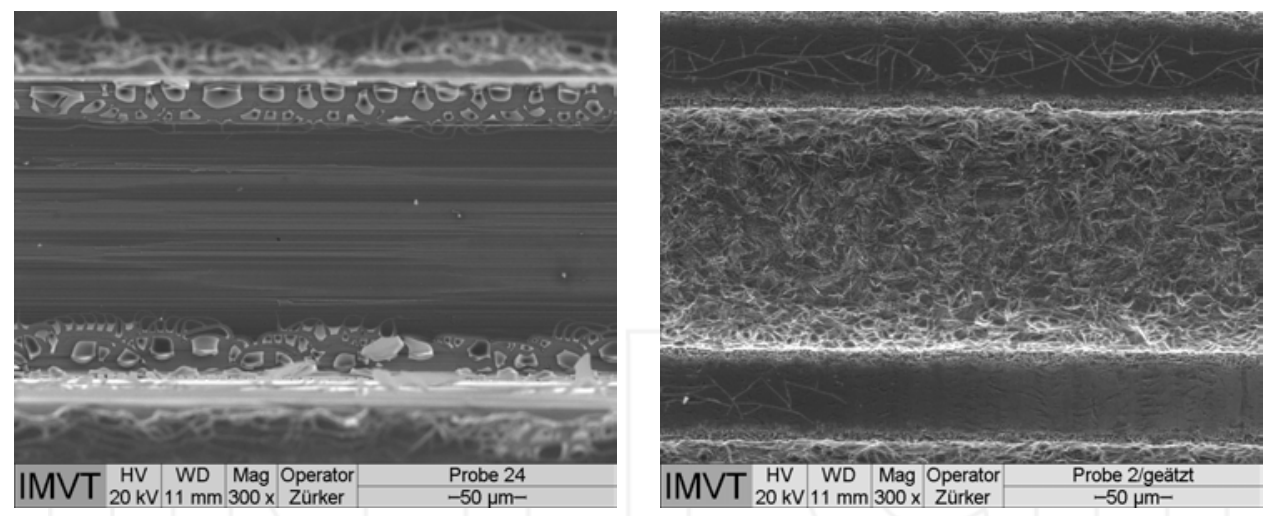

Fig. 5. Alumina layers on 316 L (1.4404) stainless steel; left: coating on mechanically fabricated rectangular microchannel; right: coating on chemically etched microchannel.

The methods to test the adhesion properties are dependent on the type of application, if it is a stationary application or if the microreactor is operated in transient mode. Mobile applications like reformer for fuel cell applications have special demand for vibration resistance of the coating. A procedure for the testing can be the determination of the weight difference after putting an adhesive tape on top of the catalyst layer and its removal or slight bending of the metallic microstructure. Some kind of standardized tests is proposed in Schwarz et al. (2010) - the loss of catalyst layer according to DIN EN ISO 4624 (bending test).

\subsubsection{Chemical compatibility}

Chemical compatibility can be discussed in three different ways: the compatibility with regard to the adhesion (discussed before), the compatibility with regard to the reaction gases and the diffusion of species from the catalyst into the metallic microchannel wall or vice versa (see section 2.3.4). Special attention should also be paid on the interaction between catalytically active species and the metal microstructure, since the electronic properties of e.g. noble metals can be influenced by the metal substrate and selectivities can be shifted. This effect has been recognized very early in Pfeifer et al. (2004b), where the influence of the steel or aluminum microstructured substrate was observed for a PdZn alloy catalyst. While under the conditions of methanol steam reforming on this catalyst the main route is directly to $\mathrm{CO}_{2}$ and hydrogen, the $\mathrm{CO}$ byproduct formation increased by the contact of the PdZn with the substrate. This effect could also occur in the case of the micro packed bed approach. However, no literature addressed this issue so far. Activity of the microstructure wall with regard to conversion of reactants may very prohibitive as discussed by several authors, e.g. severe byproduct formation was found by Walter (2003) for the selective oxidation of isoprene to citraconic anhydride due to the large surface area provided in microstructured reactors. On the other hand, appropriate choice of the metal can lead to significant potential for process intensification. Myrstad et al. (2009) showed that the microstructured reactor wall made from stainless steel does not influence the product distribution or the catalyst deactivation in the Fischer-Tropsch synthesis reaction. 


\subsubsection{Development effort}

The more complex the catalyst system the longer is the time needed for formulation of a well-known powder catalyst as a coating. Using conventional catalyst, some studies have demonstrated that the use dissolved or colloidal binders like pseudo-boehmite or sodium silicate (waterglass) is not recommended. Active sites can be covered and surface area of the support can be lost, as stated by Nijhuis et al. (2001) or Groppi et al. (2000). On the other hand, some studies exist where such approach was successful. E.g. a mixture of $\mathrm{CuO} / \mathrm{ZnO} / \mathrm{Al}_{2} \mathrm{O}_{3}$ catalyst was deposited with alumina sol on stainless steel sheets by Park et al. (2004). For approaches where new precursors are needed to prepare the catalytic coating, the development time might increase by orders of magnitude. So, rapid screening of coatings on microstructured supports would be desired. These approaches have been started by Claus et al. (2001). However, the time needed for preparation of the layers and the different layer thickness from different chemical precursors are critical issues as pointed out in section 2.2.1.

\subsection{Implications of microfabrication and process}

The microfabrication and the applied processes, e.g. for bonding, as well as the application conditions can have influence on the discussion of catalyst incorporation into the microsystem. The following subsections will detail these issues further.

\subsubsection{Deactivation rate versus catalyst regeneration / removal}

One of the most critical issues for applying catalyst layers is, that strong adhesion is the demand during operation of the microreactor, but when deactivation occurs the removal of the catalyst layer may then become a challenging task. Reactor costs must be low, so that the reactor can be removed as low cost assembly, but in most cases the life cycle analysis and the life cycle costing may not allow such approach. Microchannel catalyst coating reviews by Meille (2006) or Renken \& Kiwi-Minsker (2010) give no information on catalyst removal topics.

Investigations at IMVT at KIT show that a certain potential for multiple coating with sol-gel approach is possible since the coating thickness is seldom larger than $2-3 \mu \mathrm{m}$. For alumina support the removal of the support including the catalytically active species is possible on stainless steel supports by the use of $\mathrm{NaOH}$ solutions. Cerium oxide layers and silica layers are hardly to remove but their tolerance to poisoning or deactivation is often lower than for other supports. Cerium oxide is proven to stabilize catalysts for soot tolerance in steam reforming of diesel type fuels as demonstrated by Thormann et al. (2008) and (2011). Regeneration under air atmosphere and reaction temperature led to a full recovery of the initial catalyst activity.

In first consideration on removal of catalyst from packed bed microreactors one could easily forget the phenomena of catalyst morphology changes during in-situ activation or reaction operation, sintering or densification of the catalyst bed and possible residues from reaction. Catalyst morphology changes often occur on copper catalysts due to continuous change between $\mathrm{Cu}^{+}$and $\mathrm{Cu}(0)$ species in methanol synthesis or methanol steam reforming to hydrogen. However, no issue was observed in the work of Bakhtiary et al. (2011) and Hayer 
et al. (2011). The aspect of residues from reaction can be much more challenging in the case of Fischer-Tropsch synthesis like in the work from Myrstad et al. (2009). Here a wax fraction from the catalysis remains on the catalyst and a purge flow of solvent to remove the catalyst is necessary. A purge flow of ethanol was also proven to work for charcoal catalyst removal in microstructures of the type shown in Figure 6.

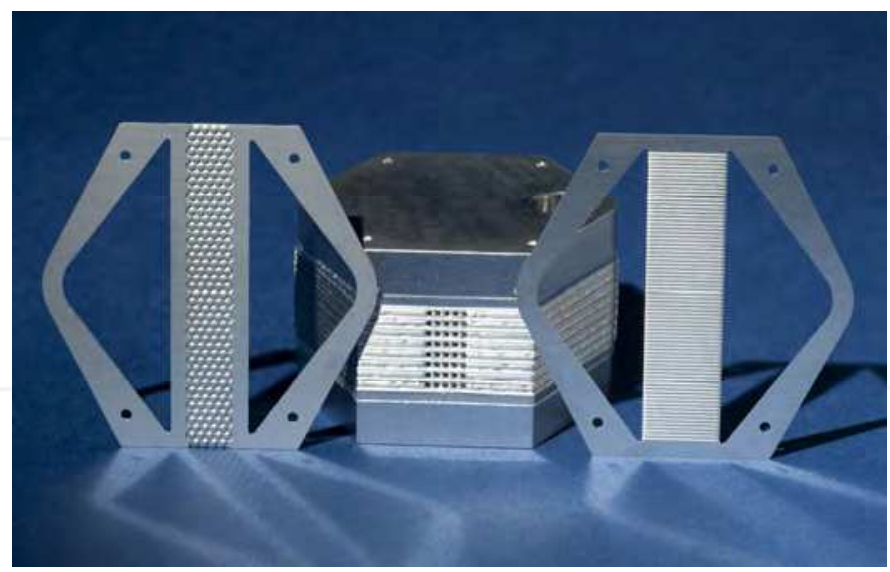

Fig. 6. Pillar type microstructures (left) and heat exchange microstructure (right) used at IMVT at KIT for the implementation of a packed bed into microreactor assemblies (middle) for several applications and catalysts, such as charcoal and alumina based catalysts.

\subsubsection{Reactor joining method}

As stated in section 2.2.1 the joining of the microstructures to a form an assembled microreactor system can be before or after the coating, suggested denotation post-coating or pre-coating respectively. Due to non-accessible walls of the microstructure in the inner part of assembled microreactors only a flow coating method can be applied, either in the liquid phase (see Fig. 7) or from the gas phase. Procedures which can apply to the flow coating are
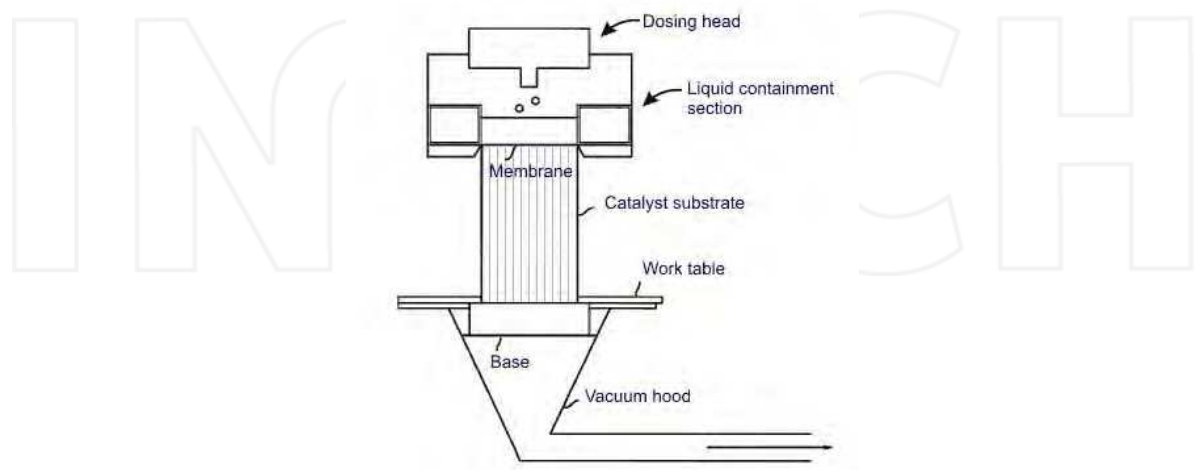

Fig. 7. Schematic of a catalyst coating apparatus used for monoliths as well as microreactors, adapted from Aderhold et al. (2003). 
liquid or suspension methods such as sol-gel technology and washcoating. However, viscosities of the fluids or suspensions and precursor loading have to be thoroughly adjusted. Too thin layers or blocking can result from inadequate composition. Rebrov \& Schouten (2011), for example, have carried out a study on the necessary viscosity for titania sols for dip-coating which could also apply for flow coating procedures.

From the gas phase only Chemical Vapour Deposition [CVD] can be applied in certain circumstances for a post-coating with catalyst. The deposition rate which is influencing the gas phase content of the support or active species precursor will determine the homogeneity of the catalyst along the microchannels. The deposition rate is mainly influenced by the parameters: microstructure wall temperature, microchannel diameter and the flow velocity in the microchannels at constant pressure. These parameters relate to the diffusivity of the precursor. Appropriateness of CVD methods for coating with $\mathrm{Al}_{2} \mathrm{O}_{3}$ has been shown very early by Janicke et al. (2000).

For the electro-assisted methods, like electrophoretic deposition and anodic oxidation of aluminum/titanium alloys as material of the microstructure have also limitations in length and shape of the microchannels. The schematic of the apparatus, unpublished so far, for such coating is shown in Figure 8. Flow of the suspension or the electrolyte is established through the microreactor assembly and the microreactor metal represents the anode. Cathodes are located in front of inlet and outlet of the microreactor. The flow rate of the suspension or the electrolyte should be high enough to avoid reduction of the particle load in the liquid or of the electrolyte ions, respectively. Bends are not allowed in the channel shape as they prevent a continuous electric field. The accessible channel length is linked with the channel size, as a decrease in channel size will reduce the strength of the electric field. Coatings produced by these methods are presented in Wunsch et al. (2002) and Pfeifer et al. (2002).

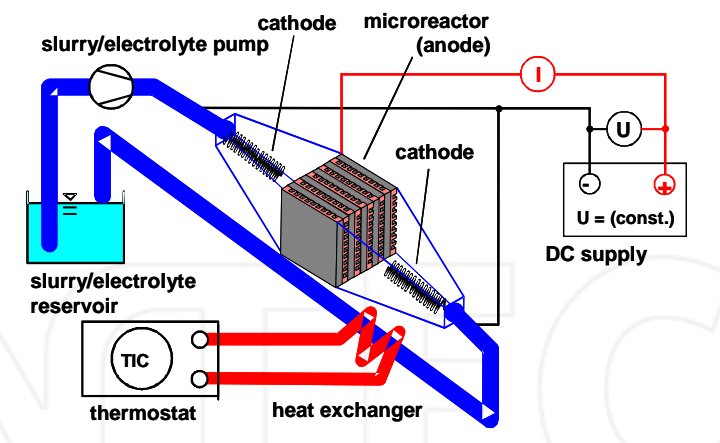

Fig. 8. Schematic of a catalyst coating apparatus for electrophoretic deposition or anodic oxidation inside assembled microreactors.

The joining methods for microstructures which end up in the necessity for flow coating are usually soldering/brazing or diffusion bonding. Temperature for these joining processes are ranging from 400 to $1400^{\circ} \mathrm{C}$ and start usually with melting of copper brazes and end up with roughly $2 / 3$ of the melting temperature of the material from which the microstructures are built for diffusion bonding. No catalyst material should be located on the bonding planes. Procedures which apply to coated microstructures are laser or electron beam welding. In the 
latter case some temperature influence on the catalyst system may be feasible near the location of the weld seam.

\subsubsection{Reactor size implications}

In practical pre-coating most of the methods known are nearly unlimited concerning the size of the plates to coat. Even for Physical Vapour Deposition [PVD] and sputtering one could imagine a very large chamber for the coating procedure. For the post-coating some size and shape limit exists as pointed out in the previous section. For CVD, anodic oxidation and electrophoretic deposition the highest limitations exist. Larger catalyst bed heights are not necessarily a problem regarding the pressure drop due to low particle sizes $(50-150 \mu \mathrm{m})$ in the micro packed bed approach, as reported by Myrstad et al. (2009).

The joining methods may have additional limitations regarding the materials and by that possibly on the outer size of the reactor. Materials, like aluminum and titanium, which tend to segregate oxygen-rich surface species, are hardly to join by diffusion bonding. The same is true for material with temperature sensitive segregation of phases. Since the material implies again some limitations in the catalyst coating procedure and by this on the total reactor size.

The microstructure size, e.g. microchannel width and height, which belongs to the reactor size attributes, is influenced by the microfabrication method. The individual microfabrication methods imply different surface roughness and shape, and impact on the catalyst incorporation technique is obvious.

\subsubsection{Migration effects}

Migration effects can occur between the metal microstructure and the catalyst due to soldering/brazing materials or in course of operation in reaction medium. Copper and silver as brazing components have high diffusivity and can mix up with e.g. noble metals like palladium or platinum. The migration effects occurring under reaction conditions were investigated by Enger at el. (2008). They found that, under conditions of methane partial oxidation to synthesis gas, the alumina layers created from annealing aluminum-rich FeCrAlloy ${ }^{\circledR}$ steel prevents chromium enrichment in the support and the rhodium catalytically active species. Support layers of alumina prepared by sol-gel route did not prevent a contamination of rhodium with chromium from Alloy 800 steel (Fig. 9). New investigations at IMVT show that cerium oxide is a much better inhibitor for migration.

\subsubsection{Stacking schemes and modular approaches}

Since costs for microfabrication may hinder the industrial competitiveness of microreactors, the use of optimum stacking schemes and modular approaches can be an approach to reduce the costs of the overall assembly. Reducing the number of microstructured plates for cooling/heating of catalytically modified microstructured plates will automatically reduce the costs. This changes also the stacking scheme. In the ideal temperature controlled situation each plate with integrated catalyst is adjacent to a microstructure for heating/cooling (alternating stacking scheme 1:1). Under reduced costs several plates with catalyst will be adjacent to each other. With regard to the catalyst temperature control, the heat conduction in the walls of the microreactor has to be described. A pseudo-homogenous approach for the description was developed therefore in Pfeifer et al. (2003). Based on a 

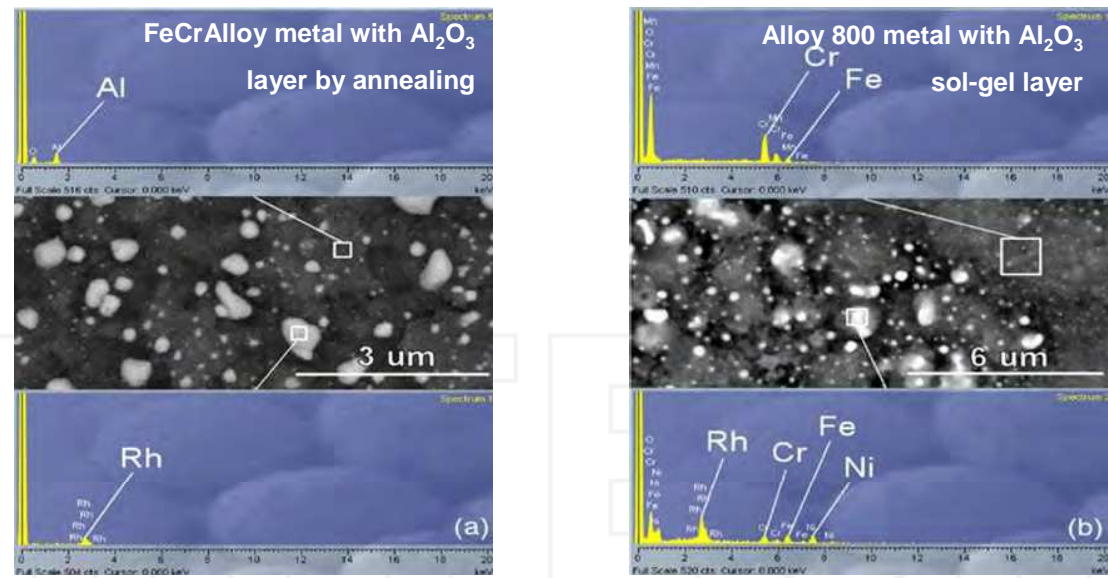

Fig. 9. Energy Dispersive X-ray Analysis and SEM of the rhodium containing alumina catalyst layer on top of the steel microstructure; a) catalyst prepared by segregation of alumina during annealing on $\mathrm{FeCrAlloy}{ }^{\circledR}$ with subsequent incipient wetness impregnation with rhodium precursor, b) sol-gel alumina layer with rhodium by incipient wetness impregnation on alloy 800 .

volumetric heat production rate due to reaction the stack temperature gradient can be calculated.

$$
\Delta \mathrm{T}=\frac{\left|\dot{\mathrm{q}}_{\mathrm{V}}\right| \mathrm{s}_{\max }^{2}}{2 \lambda_{\text {wall }}}
$$

The volume basis for this simple model is the material of the fins or pillars between the channels or in the slits, respectively. This specific volume is responsible for transport through a stack of several catalytically modified microstructured plates without intermediate cooling or heating. Assumption for this simple solution of the heat transport equation is a temperature constant heat production rate, so that only small predicted gradients fit the experiment. The stack height without intermediate cooling/heating is $2^{*} \mathrm{~S}_{\max }$.

Modular approaches, meaning that several stacks of microstructures are operated in parallel or series, can help to reduce the reactor size implications but a maintenance and fluid distributions strategy amongst the modules has to be developed for process control. Also the costs reduction for fabrication will not necessarily be significant by increasing the number of modules. This might then lead to low economies of scale in chemicals production with the microreactor system.

\subsubsection{T/p-requirements}

The temperature and pressure requirements of the chemical process which should be conducted on the catalyst integrated in the microreactor are influencing the method of catalyst implementation with regard to the material choice. High temperatures of 
more than $600^{\circ} \mathrm{C}$ imply the use of materials like alloy 800 or FeCrAlloy ${ }^{\circledR}$, whereas stainless steel is sufficient below that temperature under moderate pressure conditions. Above $950^{\circ} \mathrm{C}$ the thin walls between the microchannels or microstructures get attacked by high temperature corrosion and the problem of metal choice is not sufficiently solved there.

With regard to the pressure resistance, diffusion bonding and soldering presumably are the methods of choice for the joining procedure, which limits the materials for the microstructure and thus the catalyst integration technique.

\section{Conclusion}

The individual parameters which influence the choice of the catalyst with regard to reaction engineering, material science and fabrication issues are discussed. The crosslink between the individual parameters is shown on basis of some reaction engineering examples and relevant literature is cited. Indications for the design of microreactors are given by criteria, which allow for judgement of necessary efforts for miniaturisation.

However, it becomes obvious that there is no clear overall indication which way of catalyst integration is the best for obtaining the highest degree of process intensification with minimum investment and lowest operation costs. Every chemical process has to be judged on its own, before the choice for the approach is done.

\section{Acknowledgment}

I would like to thank all the colleagues, co-workers and $\mathrm{PhD}$ students for contributing to this book chapter in experimental and theoretical background. My special thanks also go to Hilde, Hamid, Fatemeh, Xuyen, Ingrid, Björn, Rune and Anders in Norway for the long lasting nice collaboration.

\section{List of symbols}

$\begin{array}{ll}\mathrm{a}_{\mathrm{g}} & \text { Heat transfer coefficient at catalyst layer } \\ \mathrm{a}_{\mathrm{p}, \mathrm{g}} & \text { Heat transfer coefficient at catalyst particle } \\ \mathrm{c}_{\mathrm{i}, \mathrm{bulk}} & \text { Concentration of species i in the gas (fluid) bulk phase } \\ \mathrm{c}_{\mathrm{i}, \mathrm{g}} & \text { Concentration species i in the gas (fluid) phase at catalyst surface } \\ \delta_{\mathrm{cat}} & \text { Catalyst layer thickness } \\ \delta_{\mathrm{g}} & \text { Thickness of laminar heat transfer layer } \\ \mathrm{D}_{\mathrm{i}}^{\text {eff }} & \text { Effective diffusion coefficient species i in the solid catalyst } \\ \mathrm{E} & \text { Surface enhancement factor } \\ \mathrm{E}_{\mathrm{A}} & \text { Activation energy } \\ \varepsilon & \text { Porosity } \\ \eta & \text { Pore efficiency } \\ \Delta \mathrm{H}_{\mathrm{R}} & \text { Reaction enthalpy } \\ \mathrm{k}_{\mathrm{g}} & \text { Mass transport coefficient } \\ \lambda_{\mathrm{eff}} & \text { Effective catalyst heat conduction coefficient } \\ \lambda_{\mathrm{g}} & \text { Heat conduction coefficient gas (fluid) }\end{array}$


$\lambda_{\text {wall }}$ Heat conduction coefficient microchannel wall

$\mathrm{n} \quad$ Reaction order

$\mathrm{O}_{\text {cat,BET }}$ Catalyst inner surface, measured by BET method

$\mathrm{O}_{\text {cat, geo }}$ Catalyst geometric surface

$\mathrm{O}_{\text {wall,geo }}$ Geometric surface of the microchannel

$\dot{\mathrm{q}}_{\mathrm{V}} \quad$ Volumetric heat production rate due to reaction

R Gas constant

$r_{\text {channel }}$ Radius of the microchannel

$r_{p} \quad$ Mean catalyst particle radius

$r_{v, \text { eff }}$ Observed volumetric reaction rate

$\mathrm{s}_{\max } \quad$ Half of the microchannels stack height

$\mathrm{s}_{\text {wall }}$ Thickness microchannel wall

$\mathrm{T}_{\mathrm{g}} \quad$ Gas (fluid) temperature

$\mathrm{T}_{\mathrm{R}} \quad$ Reaction temperature

$\mathrm{T}_{\mathrm{s}} \quad$ Solid (catalyst) temperature

$\Delta \mathrm{T} \quad$ Temperature gradient in the microchannel stack

$\mathrm{V}_{\text {cat }} \quad$ Catalyst volume

\section{References}

Aderhold, D., Haynes, A.G., Spencer, M.L.W. \& Winterborn D.J.W. (2003). Monolith coating apparatus and method therefore, US Patent 6,599,570 (Johnson Matthey).

Anderson, J.B. (1963). A criterion for isothermal behaviour of a catalyst pellet. Chemical Engineering Science, Vol. 18, 147-148.

Bakhtiary, H.D. (2010). Performance assessment of a packed bed microstructured reactor heat exchanger for methanol synthesis from syngas. PhD Thesis, NTNU, Norway, 2010:205.

Bakhtiary, H.D., Hayer, F., Phan, X.K., Myrstad, R., Venvik, H.J., Pfeifer, P. \& Holmen, A. (2011), Characteristics of an Integrated Micro Packed Bed Reactor-Heat Exchanger for methanol synthesis from syngas. Chemical Engineering Journal, Vol. 167, 496503.

Claus, P., Hönicke, D. \& Zech, T. (2001). Miniaturization of screening devices for the combinatorial development of heterogeneous catalysts. Catalysis Today, Vol. 67, Iss. 4, 319-339.

Enger, B.C., Walmsley, J., Bjoergum, E., Loedeng, R., Pfeifer, P., Schubert, K., Holmen, A. \& Venvik, H.J. (2008). Performance and SEM characterization of Rh impregnated microchannel reactors in the catalytic partial oxidation of methane and propane. Chemical Engineering Journal, Vol. 144, 489-501.

Görke, O. \& Pfeifer, P. (2011). Preferential CO oxidation over a platinum ceria aluminia in a microchannel reactor with distributed gas feeding. International Journal of Hydrogen Energy, Vol. 36, 4673-4681.

Görke, O., Pfeifer, P. \& Schubert, K. (2009). Kinetic study of ethanol reforming in a microreactor. Applied Catalysis A: General, Vol. 360, 232-241.

Groppi, G., Cristiani, C., Valentini, M. \& Tronconi, E. (2000). Development of novel structured reactors for highly exothermic reactions. Proceedings of the 12th 
International Congress on Catalysis, Studies in Surface Science and Catalysis, Vol. 130, $2747-2752$.

Hayer, F, Bakhtiary, H.D., Myrstad, R., Venvik, H., Pfeifer, P. \& Holmen, A. (2011), Synthesis of Dimethyl Ether from Syngas in a Microchannel Reactor - Simulation and Experimental Study. Chemical Engineering Journal, Vol. 167, Iss. 2-3, 610615.

Janicke, M.T., Kestenbaum, H., Hagendorf, U., Schüth, F., Fichtner, M. \& Schubert, K. (2000). The Controlled Oxidation of Hydrogen from an Explosive Mixture of Gases Using a Microstructured Reactor/Heat Exchanger and $\mathrm{Pt} / \mathrm{Al}_{2} \mathrm{O}_{3}$ Catalyst. Journal of Catalysis, Vol. 191, 282-293.

Klemm, E., Döring, H., Geißelmann, A. \& Schirrmeister, S. (2007). Mikrostrukturreaktoren für die heterogene Katalyse. Chemie Ingenieur Technik, Vol. 79, No. 6, p. 697706.

Knochen, J., Güttel, R., Knobloch, C. \& Turek, T. (2010). Fischer-Tropsch synthesis in millistructured fixed-bed reactors: Experimental study and scale-up considerations, Chemical Engineering and Processing. Vol. 49, 958-964.

Kölbl, A., Pfeifer, P., Kraut, M., Schubert, K., Fichtner, M., Liauw, M.A. \& Emig, G. (2004). Characterization of Flow Distribution in Microchannel Reactors. Chemical Engineering and Technology, Vol. 27, Iss. 6, 671-675.

Kreuder, H., Pfeifer, P. \& Dittmeyer, R. (2011). Catalyst preparation for dehydrogenation of cycloalkanes in a microreactor. 1st International Symposium on Chemistry of Energy Conversion and Storage [ChemEner], February 27th to March 2nd 2011, Berlin Germany, Poster No. 20.

Lopes, J.P., Cardoso, S.S.S. \& Rodrigues, A.E. (2011). Criteria for kinetic and mass transfer control in a microchannel reactor with an isothermal first-order wall reaction. Chemical Engineering Journal, doi:10.1016/j.cej.2011.05.088.

Mears, D.E. (1971). Tests for Transport Limitations in Experimental Catalytic Reactors. Industrial Engineering Chemistry Process Design and Development, Vol. 10, 541547.

Meille, V. (2006). Review on methods to deposit catalysts on structured surfaces. Applied Catalysis A - General, Vol. 315, 1-17.

Myrstad, R., Eri, S., Pfeifer, P., Rytter, E. \& Holmen, A. (2009). Fischer-Tropsch synthesis in a microstructured reactor. Catalysis Today, Vol. 147, Suppl. 1, 301-304.

Nijhuis, T.A., Beers, A.E.W., Vergunst, T., Hoek, I., Kapteijn, F. \& Moulijn, J.A. (2001). Catalysis Reviews, Science and Engineering, Vol. 43, 345-380.

O'Connell, M., Kolb, G., Schelhaas, K.-P., Wichert, M., Tiemann, D., Pennemann H. \& Zapf R. (2011). Towards mass production of microstructured fuel processors for application in future distributed energy generation systems: A review of recent progress at IMM. Chemical Engineering Research and Design, doi:10.1016 /j.cherd.2011.08.002

Park, G.-G., Seo, D.J., Park, S.-H., Yoon, Y.-G., Kim, C.-S. \& Yoon W.-L. (2004). Development of microchannel methanol steam reformer. Chemical Engineering Jorunal, Vol. 101, 87-92. 
Pfeifer, P. \& Schubert K. (2008). Hot wire anemometry for experimental determination of flow distribution in multilayer microreactors. Chemical Engineering Journal, Vol. 135, Supplement 1, S173-S178

Pfeifer, P., Görke, O. \& Schubert, K. (2002). Waschcoats and electrophoresis with coated and uncoated nanoparticles on microstructured metal foils and microstructured reactors. Proceedings of IMRET 6, AIChE Spring Meeting Pub. 164, 281-287.

Pfeifer, P., Haas-Santo, K. \& Görke, O. (2009). Application and Operation of Microreactors for Fuel Conversion, in Handbook of Micro Process Engineering, Eds. V. Hessel, A. Renken, J.C. Schouten, and J. Yoshida, Vol. 2: Devices, Reactions, Applications, Wiley, 405-420.

Pfeifer, P., Schubert, K., Liauw, M.A. \& Emig G. (2004). Characterization of flow distribution in microchannel reactors. AIChE Journal, Vol. 50, Iss. 2, 418-425.

Pfeifer, P., Schubert, K., Liauw, M.A. \& Emig G. (2004b). PdZn-Catalysts prepared by washcoating microstructured reactors. Applied Catalysis A - General, Vol. 270, 165175.

Pfeifer, P., Schubert, K., Liauw, M.A. \& Emig, G. (2003). Electrically heated microreactors for methanol steam reforming. Chemical Engineering Research and Design, Vol. 81, A7, 711-720.

Pfeifer, P., Zscherpe, T., Haas-Santo, K. \& Dittmeyer, R. (2011). Investigations on a Pt/ $\mathrm{TiO}_{2}$ catalyst coating for oxidation of $\mathrm{SO}_{2}$ in a microstructured reactor for operation with forced decreasing temperature profile. Applied Catalysis A: General, Vol. 391, 289296.

Rebrov, E.V. \& Schouten J.C. (2011). Limiting withdrawal rate and maximum film thickness during dip-coating of titania sols onto a $\mathrm{Si}$ substrate. Chemical Engineering and Processing: Process Intensification, doi:10.1016/j.cep.2011.05.025.

Rebrov, E.V., Schouten, J.C. \& de Croon M.H.J.M. (2011). Single-Phase Fluid Flow Distribution and Heat Transfer in Microstructured Reactors. Chemical Engineering Science, Vol. 66, Iss. 7, 1374-1393.

Renken, A. \& Kiwi-Minsker, L. (2010), Microstructured Catalytic Reactors, Advances in Catalysis, Vol. 53, 47-122.

Schirrmeister, S., Büker, K., Schmitz-Niederau, M., Langanke, B., Geißelmann, A., Becker, F., Machnik, R., Markowz, G., Schwarz, T. \& Klemm, E. (2006). Katalytisch beschichtete Träger, Verfahren zu dessen Herstellung und damit ausgestatteter Reaktor sowie dessen Verwendung. EP 102005019000 A1, 26.10.2006.

Schwarz, T., Schirrmeister, S., Döring, H. \& Klemm, E. (2010). Herstellung von Wandkatalysatoren für Mikrostrukturreaktoren mittels Niederdruckspritztechnologie, Chemie Ingenieur Technik, Vol. 82, 921-928.

Thormann, J., Pfeifer, P. \& Kunz U. (2011). Dynamic Performance of Hexadecane Steam Reforming in a Microstructured Reactor. Chemical Engineering Journal, doi:10.1016/j.cej.2011.08.011.

Thormann, J., Pfeifer, P., Schubert, K. \& Kunz U. (2008). Reforming of diesel fuel in a micro reactor for APU systems. Chemical Engineering Journal, Vol. 135, Suppl. 1, S74S81.

Walter, S. (2003). Mikrostrukturreaktoren für selektive Oxidationsreaktionen: Isopren zu Citraconsäureanhydrid. PhD Thesis, Shaker, Aachen, 2003. 
Wunsch, R., Fichtner, M., Görke, O., Haas-Santo, K. \& Schubert, K. (2002), Process of applying $\mathrm{Al}_{2} \mathrm{O}_{3}$ coatings in microchannels of completely manufactured reactors. Chemcal Engineering and Technology, Vol. 25, 700-703.
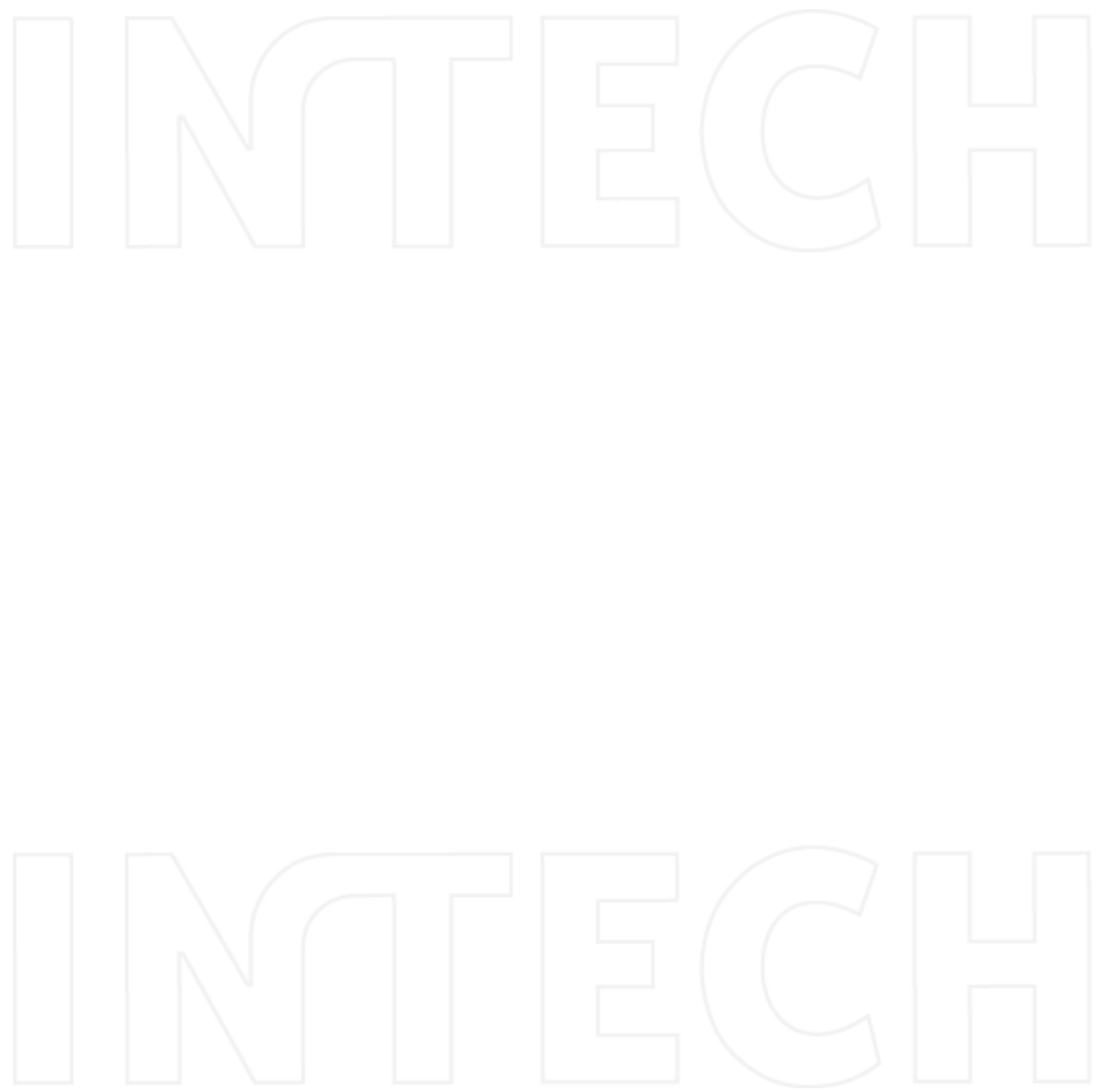


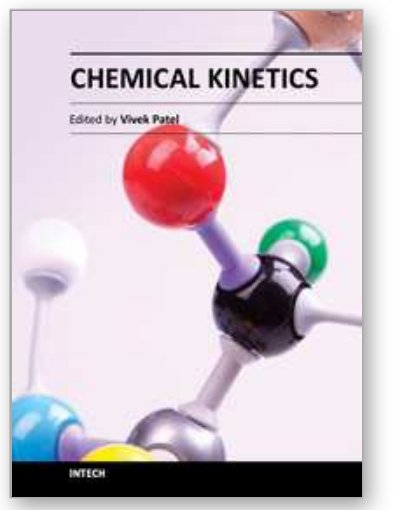

\author{
Chemical Kinetics \\ Edited by Dr Vivek Patel
}

ISBN 978-953-51-0132-1

Hard cover, 344 pages

Publisher InTech

Published online 29, February, 2012

Published in print edition February, 2012

Chemical Kinetics relates to the rates of chemical reactions and factors such as concentration and temperature, which affects the rates of chemical reactions. Such studies are important in providing essential evidence as to the mechanisms of chemical processes. The book is designed to help the reader, particularly students and researchers of physical science, understand the chemical kinetics mechanics and chemical reactions. The selection of topics addressed and the examples, tables and graphs used to illustrate them are governed, to a large extent, by the fact that this book is aimed primarily at physical science (mainly chemistry) technologists. Undoubtedly, this book contains "must read" materials for students, engineers, and researchers working in the chemistry and chemical kinetics area. This book provides valuable insight into the mechanisms and chemical reactions. It is written in concise, self-explanatory and informative manner by a world class scientists in the field.

\title{
How to reference
}

In order to correctly reference this scholarly work, feel free to copy and paste the following:

Pfeifer Peter (2012). Application of Catalysts to Metal Microreactor Systems, Chemical Kinetics, Dr Vivek Patel (Ed.), ISBN: 978-953-51-0132-1, InTech, Available from: http://www.intechopen.com/books/chemicalkinetics/application-of-catalysts-to-microreactor-systems

\section{INTECH}

open science | open minds

\author{
InTech Europe \\ University Campus STeP Ri \\ Slavka Krautzeka 83/A \\ 51000 Rijeka, Croatia \\ Phone: +385 (51) 770447 \\ Fax: +385 (51) 686166 \\ www.intechopen.com
}

\author{
InTech China \\ Unit 405, Office Block, Hotel Equatorial Shanghai \\ No.65, Yan An Road (West), Shanghai, 200040, China \\ 中国上海市延安西路65号上海国际贵都大饭店办公楼405单元 \\ Phone: +86-21-62489820 \\ Fax: $+86-21-62489821$
}

